

\title{
TRANING ON HAND WEAVING SKILLS FOR MENTALLY CHALLENGED PEOPLE USING MULTIMEDIA PROGRAM
}

Prof. PHD. Samia Ahmed Elsheikh,

PHD. Ahmed Hatem Said,

Maii Ateia,

Helwan University, Egypt, 
Hand weaving, Mental-ill people, Multimedia, Looms, Vocational therapy, Plain weave

Currently, the world looks to make benefit of the abilities of children and adults who have difficulties in learning by making use of the Vocational Therapy programs. This program is used in parallel to the Structured Rehabilitation Program and is designed to rehabilitate persons who lost the ability to wok because of a disease or a disability which help them to participate into work again. This programs works on the individuals with their current physical and mental conditions to determine the suitable work for them. It deals with each individual's condition, skills and tendencies through a set of tests.

Some teachers who deal with children with learning difficulties classify the problems that usually appear in these children to 11 kinds of problems that is known as class learning difficulties, considering that these problems are realistic rather than virtual ones. This study focuses on 2 of these kinds:

1. Counting and identifying numbers,

2. Motor Coordination

\section{Difficulties indicators:}

Learning difficulties in children contended in the following:

- Difficulties in identifying objects

- Difficulties in visual-motor synergy that causes difficulties in the coordination between the eye, hand and figures motions

- Slowness in dealing with numbers, multiplication concepts, mathematical equation conversions, and difficulties in verbal problems understanding and their indications like bigger than and smaller than.

\section{Behavioral and social characteristics for children with learning difficulties:}

- Misbehaviors, social skills usage difficulties because of missing the ability of talking and interchanging ideas and concepts with people as a result of difficulties in the language and expressions or dash and recklessness in haphazard responding and acting.

- Tensions, stress and disorder resulting from the interfering of emotions that are swinging between their intelligence levels that is equals to or exceeds their pears and not competing with them to achieve academic success.

- Low self esteem and self confidence, missing the motivation for learning because of falling in achieving success in school academic realizable tests.

- Withdrawal and insularity and escaping from society, school absence, depression feelings as a result of a social away from their pears, families and teachers.

- Haphazard and lack of system in all life sides either in work, locations, or times. This refers to missing stability related to time and place and the mental disorientation that they live.

- Difficulties and weaknesses in visual-motor synergy that leads to stability difficulties and difficulties in following the letters and numbers sequencing and motions alternating which makes it difficult to tune the rhythm for any moving object.

\section{Behavioral characteristics for mental superiority, creativity and talents for children with learning difficulties:}

- District wide fertile imagination and their ability to control it and direct it to create imaginary pictures that may convert in the realistic world to discoveries and inventions which push them to continue in day dreaming as a way to escape from reality, problem solving or intelligent vision that will formulate only in the imagination of these children.

(AmeSea Database - ae - April. 2015- 0029) 
- Thinking and realizing in these children depends on imaginary pictures with different dimensions using their senses but they can't realize words or intangible symbols that can't be imagined or visualized.

- Crazy or strange ideas that sometimes arise in their imagination and seem unrealistic but time shows a real intelligent.

Due to the contradicting characteristics that children with learning difficulties have which is often related to imaginations, this study believes that the art education field is one of the most suitable fields that can provide many experiences and skills that help to launch these characteristics in a positive direction if the frame of enjoyment while practicing arts. In addition, it is the side that is related to utilizing the art education fields in training this category of children on many different skills which qualify them later in areas of life.

Hand weaving field as one of the art education fields is seen a rich field to apply many experiences that develop many creativity and motor abilities in addition to the mathematical operations and in the same time producing hand woven pieces depending on hand skills such as yarn winding and weaving which develop physiological areas. This study's idea came up by meditation these children characteristics and the operations and skills that are included in the hand weaving field. It was so important to add many modifications to the known weaving tools to suit the application nature with these children; this led to producing a group of tools and media that this study depended on during the application.

Weaving skills:

This is included in the following 2 sides:

1. Artistic side

a. Color design ( Color effects)

2. Technical Side

b. Weaving design (Weaving construction) $\longrightarrow$ Visual Experiences

a. Loom

b. Warping

c. Weaving

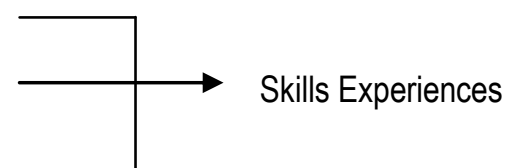

The artistic side:

The artistic side is the group of practices that form the artistic essence of the weaving piece and it is the visual experiences. This is divided into the following 2 factors

1. Color design which is related to the color effects that is resulted from combining yarns colors where the diversity color theme for the warp and the weft leads to a many variable coloring, since the thread colors have a significantly clear and important role in weaving.

2. Weaving construction: Weaving construction is an important factor in the artistic weaving site. And has an important and basic role in building weaving pieces. Weaving construction is considered a creative operation targeted at completion of the purpose, whether functional or aesthetic. That helps in satisfying the needs of people and their sense of beauty. It is the design related to weaving construction. It shows how the warp and weft are interlaced together to form the tissue. There are different kinds of weaving constructions which moves progressively from simple to complicated. When color design and weaving contraction are combined, a distinctive woven art is produced with the artist soul. At the end, it is a range of visual experiences that reflect the character of the artist and enriches the viewer experiences.

\section{The technical side}

The technical side is based on the loom, warping and weaving. Those three factors are responsible for developing the skill experiences. The loom is the tool to create the weaving and it comes in many shapes and many functions such as frame looms and table looms. Warping is the second factor which varies from one loom to the other, depending on its kind. The third factor is weaving, which deals with the artistic stage of the whole operation. Weaving includes the experience of forming using designs and materials to create many 
artistic possibilities in hand weaving. The more integration between the artistic side and the technical side, the more successful art production and skill development occurs.

Through the previous review of the hand weaving experiences "Artistic and technical" which give the enjoyment while practicing especially to children who have difficulties in learning. Thus, it was so important to make some modifications to the hand loom to suit the application nature of the current experiment that is applied to the children of this study.

\section{Media and Tools}

Media is not just a group of learning material but it is a complete system based on connecting the media in a special system. The role for each media is distributed under the umbrella of the whole system. Furthermore, all media are incorporated together to form an integrated system that its elements interact in an educational program. This works as a whole complete entity despite its breadth and diversity of forms and purposes.

Multimedia is distinguished with several properties that make it enjoyable and effective educational tools. The interactivity of these tools is considered as a major part of the learning process. The bilateral communicative educational environment in learning positions and the freedom of moving from one level to another help in approaching a better learning. Additionally, the integration between all media elements insures a homogeneous learning process. Diversity in addressing the senses and the individuality in handling themes is achieved by the variation of these tools.

Mary Hitfield and Ericson determined some if the special sides to use the multimedia in the education process as following:

- The increase of the spontaneous and self activity for the learner and its positive enhancement

- The opportunity to interact between the learner and the multimedia tools

- Helps the growth of the learner's ability in making decisions and solving problems

- Providing the learner with many opportunities to access information

- Taking into account individual differences among learners in terms of their abilities and learning styles

- Allow sufficient time for the learner to achieve effective learning

- Great flexibility in access to information

- Dependence on the nature of the multiplicity of senses of the human person

- The possibility of dealing with large amount of information

- Boost the learning process and make it durable by increasing the use of senses and interaction with the media

Therefore, the current study tended to design a set of tools and media to achieve the objective of the study to develop diverse experiences in children with learning difficulties through the application of the experiment of the this study, which focuses on the development of 2 key aspects considered the most important difficulties faced by this group of children as follows:

- Motor synergy

- Counting and simple mathematical operations

This is done through a proposed program for a group of hand weaving experiences that test and direct the skills and viability of the children and their tendencies toward hand weaving practices via the multimedia tools that are proposed in this study.

\section{Aspects supported by the proposed multimedia:}

- Positive role of the learner in his choice of colors and yarns thickness used.

- The growth of the child's ability to make decisions when synthesizing various types of yarn

- The growth of the child's abilities in solving problems that may face when the synthesis of materials and colors in the process of weaving

- Provide opportunities for children to get information on the types and thickness of yarns and fabrics textures.

- Taking into account individual differences among children in terms of their ability to acquire information offered by each tool

- Provide an opportunity for effective learning and use of time available for the use of each media tool

(AmeSea Database - ae - April. 2015- 0029) 
- The multimedia addresses many of the senses in children, and most important of senses of touch and vision through colors and touching yarns.

- Help on a comparison between the nature of each material in terms of how matt or transparent.

- Gain different experiences of hand weaving in a fun and enjoyable performance.

- The process of acquisition of counting skills through weaving process, as the results of the count directly appear in the implementation process.

- Learn how to divide the number to its components during the weaving process and during the selection of the number of columns of warp.

- The stability of information by providing the opportunity to repeat the number during the weaving

- Selecting the ruler that is appropriate with the digital component and the warp, shows the child's learning concerning the woven piece.

- The opportunity to understand the specific concepts represented in the numbers when converted to the elements represented by the form of yarns and colors

- Multimedia diversity helps these children to understand and realize the idea of threaded dovetail in the fabric in an interactive and more pronounced.

This study was applied within the multimedia program that included 3 main activities using 3 different multimedia tools. These tools were designed especially for the purposes of this study -to simplify the process of weaving. During the early stages, children recognized different types of yarns, fabrics and textures that specify each of them. Additionally, this activity provided the opportunity to interchange some weaving specialized vocabularies. Then, the next phase was using an easy tool to simplify the warp and the weft interlacing process. The final stage was utilizing this amended loom so the children can experience the real weaving process in a simple way using the components of numbers and the variety of materials and applying the previous experiences. At the end of the program each individual produced a woven piece.

Following are the educational multimedia sequenced according to their usage:

\section{Yarn palette}

A group of palettes was designed for used materials in the plain weaving process from yarns with many different thicknesses, yarns with many color degrees, diverse yarn textures and a group of matt and transparent ribbons. Also, different color and texture fabrics were used. The purpose of this tool is to display a number of materials that can be used as weft. This will give children the opportunity to compare and chose the appropriate material or combine different materials considering that these palettes will be displayed all the time at the art education room during the experiment time.

This table shows the yarns and colors palettes that presents the first factor

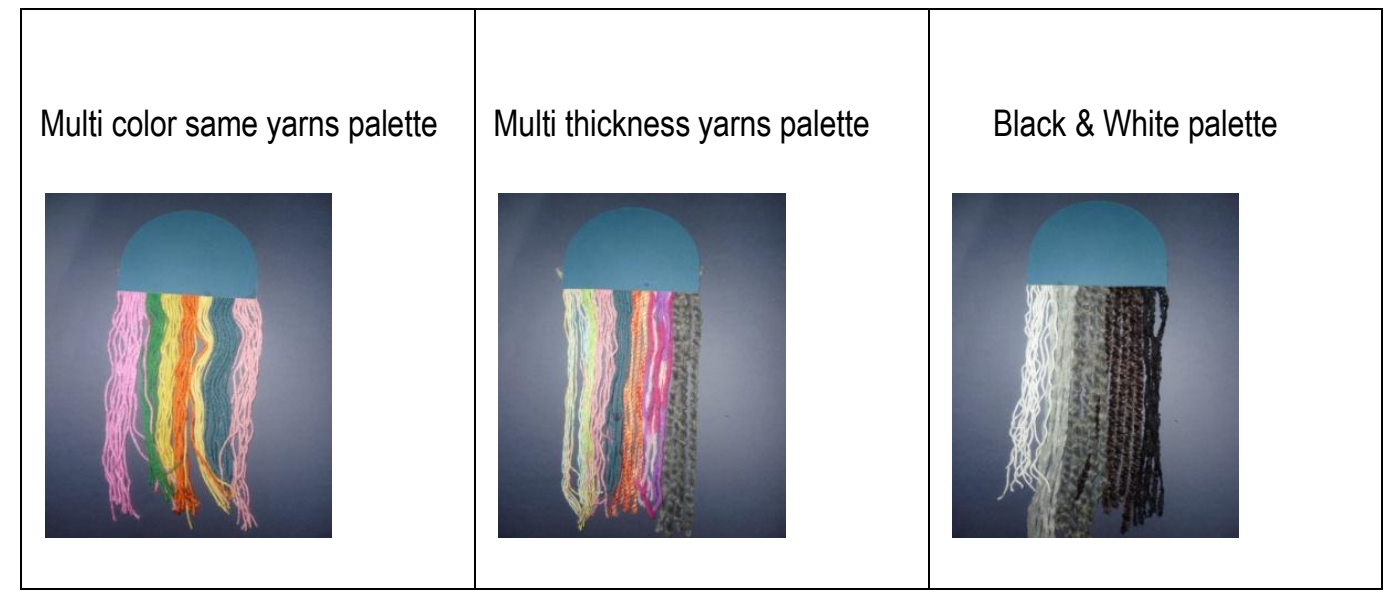

(AmeSea Database - ae - April. 2015- 0029) 


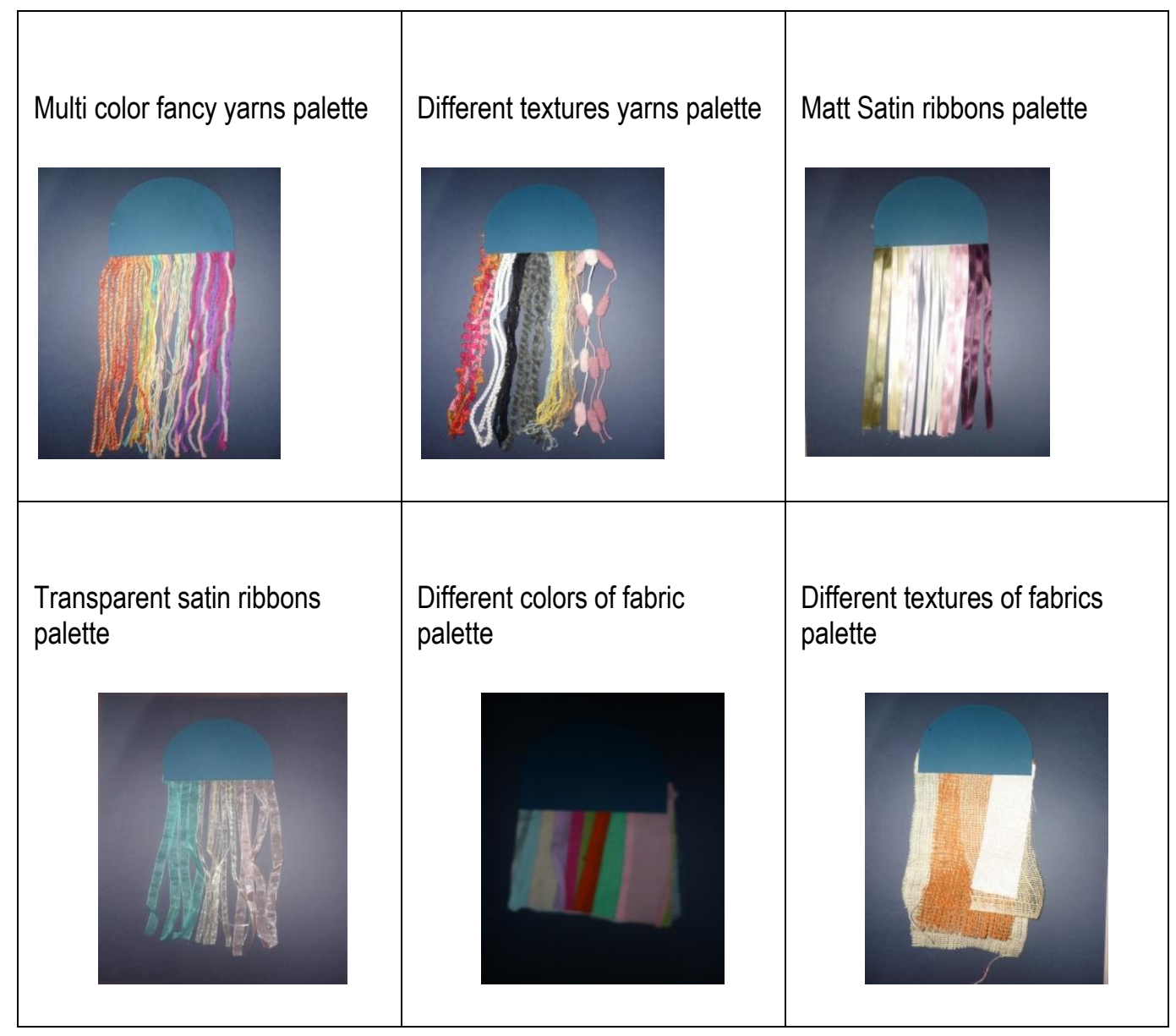

\section{Change the warp:}

This concluded in designing a tool that simplifies the loom's concept through amplifying yarn warp which its preparation is considered a considerable part of the weaving process. This warp is presented by a group of vertical bars fixed on the base that the yarns can go in between. These bars are fixed in equivalently distributed spots. This is similar to the usage of a magnifying glass focused on the yarns to enlarge it in an exaggerated manner. Exaggeration in the shape and the nature of the warp with the wooden bars is in fact what makes this tool very enjoyable to be used by children. Wood was used in the design of this tool so it will be a safe and fixable tool to perform the wanted function. Varied thicknesses was applied to simulate the diversity of yarns and are fixed in a predetermined places so children can select the thickness and then passing the yarn between the wooden bars according to the mathematical operation that the teacher explains. This is in addition to selecting the color, the thickness and the nature of the yarns that will form the warp.
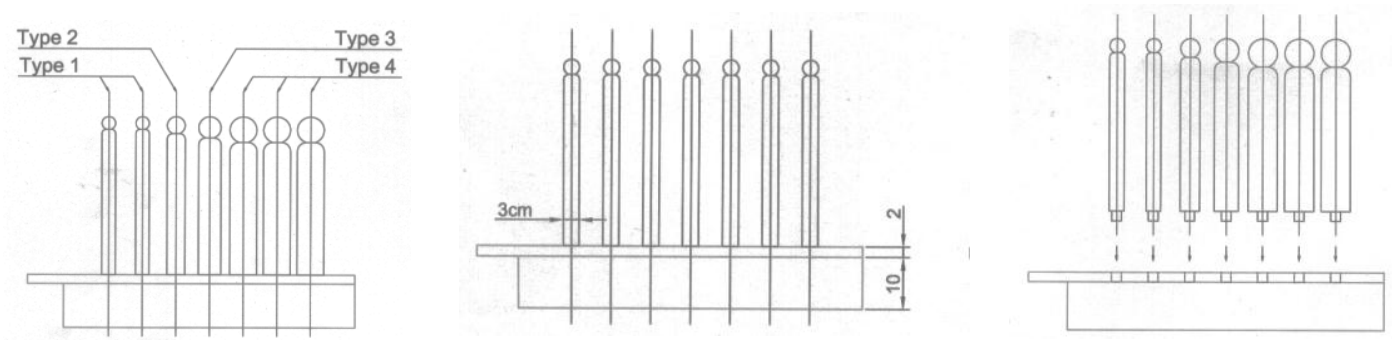

Illustrations showing the simple tool "Change the warp" weaving warp

(AmeSea Database - ae - April. 2015- 0029) 
It is clear from these illustrations that the difference in the thickness of the wooden bars representing the warp leads to diversity in the inter-spaces if the bars thickness is varied, while identical bars' thickness leads to similar inter-spaces which will affect the cognitive development of the child. This is beside the development of the artistic capacity handling diverse input data to get a variety of substantive artistic outputs.

\section{Amended Loom}

As the experience of weaving skill is to raise or reduce some of warp yarn to be able to pass the same weft threads of the work dovetail fabric, it was suggested a group of rulers to perform this function beside another educational function that is suitable for this children category which is developing the counting and calculation skills. The rulers concept is presented initially with a group if hollow rulers as in the illustration below. A mathematical system is used as a part of the qualification training for the children category aiming to develop the vocabulary of simple numbers from 1 to 5 . These rulers are divided with numbers $(1,4),(2,3),(1,2,3,4)$ as 2 rulers for each numerical system so children can test these rulers which they will operate according to the calculations of the dovetail threads in the weaving piece. It was taken into account in this amended loom, the diversity of the ruler shapes and the ease of use beside the safety factor concerning the used material to be suitable for children. Finally, with this loom, children can easily distinguish between different rulers and what each ruler can produce. The following illustration shows the shape and the parts of this loom.



A plan for the amended loom with its parts separated

Parts of the amended loom:

1. Rulers: number of rulers are 12 divided into 3 groups as in the illustration. Its function is lowering the warp in various groups to form the shed and passing the weft.

2. The sides of the loom: This is the most important part in the loom, which contains a long horizontal slit and twelve vertical slits. These slits facilitate the movement of the rulers back and forth.

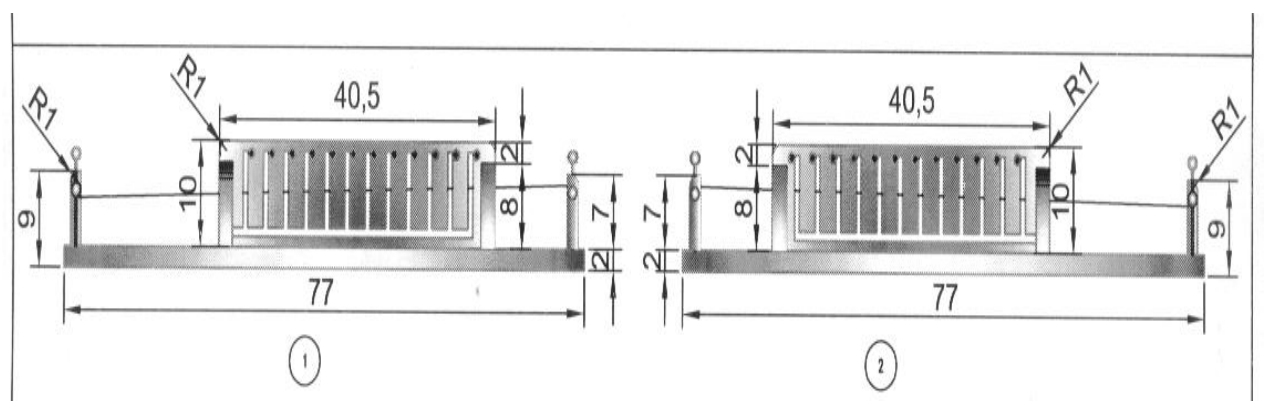

Side view of the loom shows places that control over the moving rulers

(AmeSea Database - ae - April. 2015- 0029) 
3. Back and front beams: these are 2 wooden cylinders fastened to the loom base by a wooden pin as shown on the following illustration.
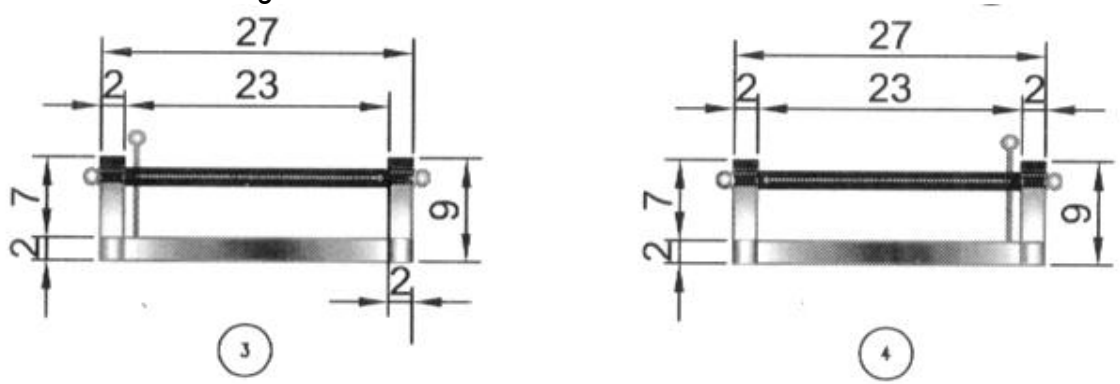

Illustration of the 2 beams with dimensions in $\mathrm{cm}$

In this amended loom, the features of frame loom and table loom were combined to suit the children with learning difficulties. At the same time, to me meet the mathematical experiences that children can perform. This tool provides the individual with a simple weaving experience so it is not important to be accurate as a professional weaving loom. It is a way for the children to enjoy the weaving experience through working with the different yarns colors, shapes and textures. Also, this lead to repeating the calculations process- that children apply after selecting the ruler - and noticing the resulted shape on the woven piece as a result of this numerical combination.

Texture construction that is used in the suggested loom:

Using rulers in this amended loom allow to have various weaving constructions are dominated by a variety of influences of the plain weave and its derivatives. This is done without the need to understand the scientific basics of weaving constructions which I not important to the children in this category. The aim of this study is to train and direct these children on hand weaving as a skill including the developing benefits. Additionally, it aims to improving the senses experiences and neuromuscular compatibility besides stressing on visual synergy in these children. Producing woven pieces support the children self confidence and their expression and production abilities.

\section{Warping the amended loom}

Warping the amended loom in a normal procedure as all warps pass tightly below rulers levels from the front beam to the back beam. Color and thickness distribution is performed according to number 5 vocabulary.

\section{Weaving process:}

Using the rulers in sequenced way to lower to warp on the base of numbers from 1 to 5 according the following procedure:

1. Lowering the first ruler to form the shed

2. Passing the weft

3. Returning the ruler to its initial position

Repeating this process while inserting weft each time will produce a weaving. This plain weave with its regular and irregular derivatives on the woven surface give different color and texture effects that become a good and easy introduction to teach the Dyslexia - Dy sgraphia - Dy scalulia children. The various movements of warp in a sequenced or haphazard numerical manner can be used to get the desired surface design. Also the children can deal with the weaving process inputs.

\section{The beauty of resulted weaving constructions}

Hand weaving is distinguished by uniqueness and innovation since the artist is the weaver himself and start the art work from the design phase by activating the artist mind to achieve a beauty target or 
a beauty benefit. During this the artist selects the material that suits the idea. Moreover, he chose the style and technique to combine all that in a creative innovational frame.

Weaving process gives children many features and factors that allow them to achieve the beauty values of weaving. This depends on the inputs that satisfy the uniqueness and constant renewal. The factors of hand weaving beauty concentrated as following:

- Color: children can chose any color from the wide selection of yarns

- Material: yarn textures and thickness varies and each has its own surface appearance

- Technique: surface constructions produced via different techniques.

The experiment was applied on a group of children with learning difficulties and the results are presented below.
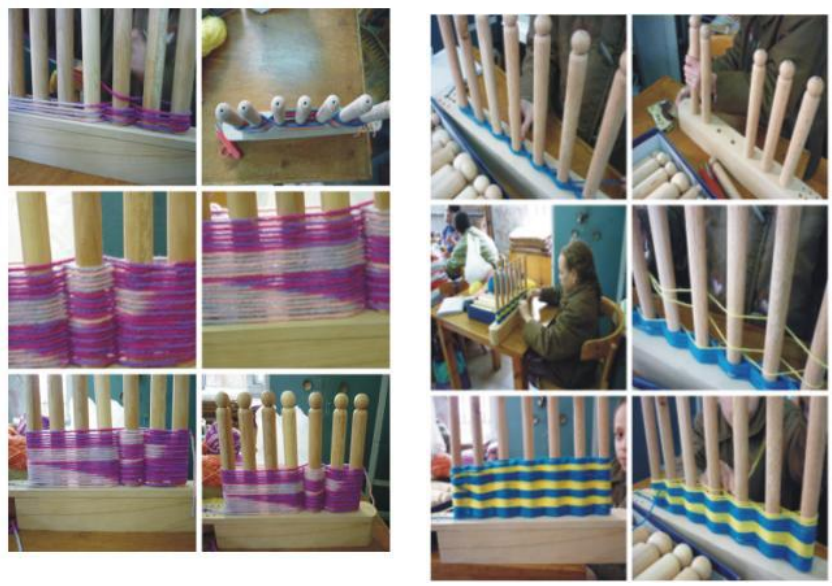

Above are a group of photos that show the children working on simplified multimedia for the process of changing the warp or warping.

This depends on the time factor. Creativity in this process depends on aligning weft thread colors and weaving on wooden looms that represent the stationary warp. Children can practice this process more than before using new color combinations. These are then photographed and the picture is then stored as a photographic result. Children can also change the combination of the loom to vary in thickness to experience the variance resulted in form.

Secondly: Medium results represented in the modified loom:

This is represented in small woven pieces that have been made on modified looms using various materials like different threads, textures and stripe sizes.

(AmeSea Database - ae - April. 2015- 0029) 


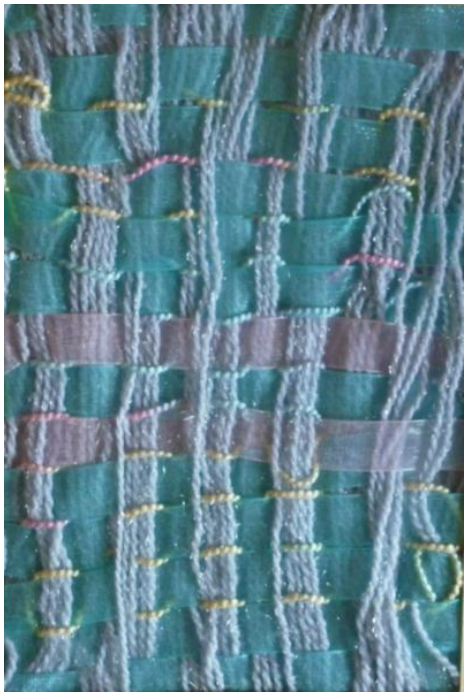

1

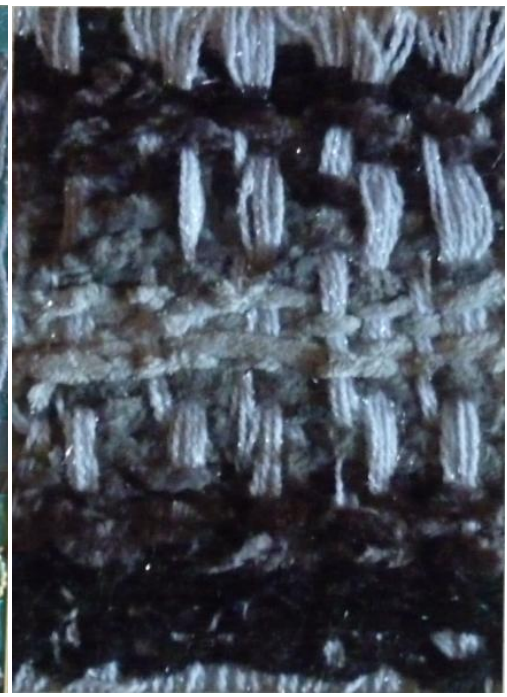

2

1. Children have used threads varying in thickness in weft and warp.

2. Children have used a group of different weaving materials.

Children have used customized looms for various weaving experiences that start from warping and until weaving. Different collections of threads have been used with organza strips that vary in thickness. Weft is passed via the consecutive inclination of warp threads using numbered rulers. From the practiced woven results it can be seen that children have succeeded in combining between threads and stripes with different textures and colors. They have been able to extract a group of woven designs that reflect a combination of weaving that extend in both directions.

Through the applicable program and its multimedia and tools, this study has reached a group of results for the most common problems that meet children with studying challenges. These can be illustrated in the below table:

\begin{tabular}{|l|l|}
\hline $\begin{array}{l}\text { Most common problems meeting learning impaired } \\
\text { children }\end{array}$ & Solutions provided by the suggested tools \\
\hline Disturbance in visual and kinetic memory & $\begin{array}{l}\text { In the process of wefting and warping, the repeating of } \\
\text { the process several times will enhance visual and } \\
\text { movement memory. The counting rulers will also be } \\
\text { linked to a certain color for every ruler which will } \\
\text { enhance visual memory. }\end{array}$ \\
\hline Problems in treating mathematical skills and information & $\begin{array}{l}\text { The child's choice of thread color, thickness, texture and } \\
\text { treating the information used in the process of wefting } \\
\text { and warping will help use mathematical operations } \\
\text { linked to the weaving process. }\end{array}$ \\
\hline Distraction and hyperactivity & $\begin{array}{l}\text { The child's determination of using a certain number of } \\
\text { columns in the process of wefting and warping } \\
\text { decreases their distraction. In addition, using a ruler in a } \\
\text { consecutive manner maintains a low level of } \\
\text { hyperactivity and distraction. When the children interact } \\
\text { in the weaving process, this definitely helps in } \\
\text { concentrating on the piece in hand and motivate to } \\
\text { reach the final product at the end. }\end{array}$ \\
\hline Difficulty and slowness in learning consecutive numbers & $\begin{array}{l}\text { The consecutive process of the modified loom in } \\
\text { passing the weft threads then reversing the process will } \\
\text { help concentrate on consecutive actions to reach the } \\
\text { final product. }\end{array}$ \\
\hline Lack of organizing and synchronization (eyes and hand) & \begin{tabular}{l} 
Using weaving combinations during the weaving \\
\hline
\end{tabular}
\end{tabular}

(AmeSea Database - ae - April. 2015- 0029) 


\begin{tabular}{|l|l|}
\hline & $\begin{array}{l}\text { process in wefting and warping in a system will help } \\
\text { develop being organized during practice. This will also } \\
\text { help develop the synchronization of eyes with hands. } \\
\text { Using the rulers in the modified loom more than once } \\
\text { will also maintain the routine in performing the weaving } \\
\text { and help eye to hand synchronization. }\end{array}$ \\
\hline Self esteem and trust issues & $\begin{array}{l}\text { Showing a woven piece for one of the children will raise } \\
\text { their self esteem and self appreciation for accomplishing } \\
\text { a woven piece and doing the job while going through all } \\
\text { its procedures of choosing the threads, colors and other } \\
\text { mathematical procedures. }\end{array}$ \\
\hline
\end{tabular}

As illustrated above, these tools can be depended upon as multimedia suitable for teach impaired children that have challenges in acquiring hand weaving skills or concepts.

\section{References:}

1. Davis, Ronald with Braun, Eldon M. : The Gift of Dyslexia, New York: $2^{\text {nd }}$ ed., The Berkley Publishing Group Adivision Penguin. Inc. (1994).

2. Hallahan, D.P. and Kauffman, J.M.: Exceptional Children Introduction to Special Education, $5^{\text {th }}$ ed, Boston: Allyn - Bacon. 1991.

3. Samia ElSheikh: Hand Weaving and Fashion Design, AIRoshed Pub. 2006.

4. Mahmoud Awad Allah, Magdy ElShahat, Ahmed Ashour: Learning Difficulties, Therapy and Diagnosis, Dar Elfekr, Cairo, 2003.

5. http://www.mdguidelines.com/vocational-therapy 